\title{
CONTRIBUIÇÃO AO DEBATE ATUAL SOBRE A FORMAÇÃO DE PROFEESSORES NO BRASIL: PELA FORMAÇÃO DE FUTURAS GERACÕES NA PERSPECTIVA DA RECONSTRUÇÃÓ DO SÓCIO-CULTURAL
}

\author{
Maria Eliza Miranda ${ }^{1}$
}

\begin{abstract}
Resumo: Este artigo é uma comunicação sobre as primeiras aproximações de resultados obtidos com a Pesquisa "Valorização da Geografia na Educação Básica" na etapa-piloto realizada entre abril e agosto de 2009 durante o Curso de Extensão Universitária "Desenvolvimento Didático-Pedagógico de Aprendizagem Mediada de Geografia para a Educação Básica". A pesquisa trata das interfaces e vinculações essenciais entre o ensino de Geografia na educação básica e as áreas de interesse que caracterizam as tendências do ensino e pesquisa em Geografia como área de conhecimento cientíicoacadêmico, as quais consolidam sua crescente importância como conhecimento complexo. Enquanto disciplina escolar a Geografia é aqui entendida como uma prática social indispensável para a formação livre e independente das representações de mundo e das representações das relações que há no mundo que circulam na sociedade e na cultura. A pesquisa de cunho qualitativo procurou caracterizar e compreender as demandas que existem atualmente em relação à formação de professores a partir das narrativas dos próprios professores sobre os enfrentamentos cotidianos dos problemas de aprendizagem que verificam em seu trabalho e que apontam a necessidade de questionar, de maneira radical, as tendências teóricas e filosóficas de cunho técnico científico que tem predominado no debate atual sobre formação de professores no Brasil. O que a pesquisa indica, até o presente momento, é, ao contrário do que poderia parecer, a necessidade de enriquecer ainda mais a formação teórica e filosófica dos professores. Foi adotada na pesquisa a concepção de aprendizagem mediada de Reuven Feuerstein, a concepção de diálogo segundo Mikhail Bakhtin, e ainda a idéia de pensamento complexo e de religação dos saberes produzidos e separados historicamente segundo Edgar Morin. As concepções adotadas formam o que denominamos de "fronteiras teóricas para a formação de professores".
\end{abstract}

Palavras-chave: Geografia; Complexidade; Formação de Professores; Aprendizagem Mediada; Dialogicidade.

\section{Introdução}

Este artigo tem a finalidade de apresentar as primeiras aproximações dos resultados da fase-piloto de desenvolvimento da pesquisa "Valorização da Geografia na Educação Básica" as quais se referem a determinadas demandas que há no ambiente escolar atualmente e que se encontram no interior das práticas pedagógicas que se efetivam no ensino fundamental e médio e se relacionam diretamente com o papel e o trabalho do professor de Geografia e com a importância e a contribuição que essa ciência tem no quadro de formação geral de professores.

A primeira demanda identificada refere-se ao preparo e formação intelectual do professor em sua dimensão filosófica, didático-pedagógica e de habilidades de pesquisa. 0 nível de assimilação e apropriação que realiza quanto à introdução das novas tecnologias em seu trabalho e como elabora a sua representação de mundo e a representação das relações que ocorrem no mundo.

A segunda demanda refere-se à formação acadêmica do professor de Geografia quanto ao domínio que apresenta em relação ao conhecimento e as tendências contemporâneas de Geografia e de Educação.

E a terceira demanda diz respeito à competência que professores devem desenvolver quanto à dimensão política da ação educativa, sua capacidade de análise de contexto e sua habilidade de filtrar e traduzir o movimento e 0 alcance das políticas públicas no ambiente escolar.

Aabordagem adotada relaciona estas demandas primeiramente aos fundamentos da formação profissional que norteiam as práticas dos professores de Geografia quanto a sua independência intelectual no tratamento e escolha dos temas e conteúdos de Geografia no ensino fundamental e médio, o domínio e a aplicação das temáticas envolvidas na esfera de códigos e linguagens, a competência de planejamento e de programação do trabalho docente, isto é, as habilidades didático-pedagógicas e a dimensão ética e de cidadania que orienta seu perfil profissional.

${ }^{1}$ Professora e Pesquisadora da Área de Licenciatura do Departamento de Geografia da Faculdade de Filosofia, Letras e Ciências Humanas da Universidade de São Paulo (elizamir@usp.br). 
As demandas apontadas também estão relacionadas à demarcação das vinculações essenciais entre a Geografia como área de conhecimento acadêmico e a Geografia enquanto disciplina escolar identificando-se as tendências atuais das práticas curriculares do ensino de Geografia e a análise dos aspectos vulneráveis dessas práticas para prospectar os fundamentos filosóficos e psicopedagógicos da aprendizagem de Geografia e definir as contribuições que 0 ensino de Geografia pode ter na aprendizagem de habilidades cognitivas envolvidas no aprimoramento de diversas competências com ênfase na competência de leitura e de escrita, compreendidas não apenas no âmbito da alfabetização propriamente dita enquanto aprendizagem da codificação e decodificação da escrita, mas no sentido mais amplo de leitura de mundo e de comunicação e expressão dessa leitura, inclusive como sistemas de representação.

Espera-se com esse trabalho contribuir para repensar novos eixos e núcleos de interesse para a área de formação de professores não apenas de Geografia, mas também de professores em geral.

\section{A Pesquisa \\ Concepções}

Consideramos aqui a Ciência Geográfica como resultado do desenvolvimento do pensamento complexo no sentido da tendência histórica apontada por Edgar Morin, que identifica como pensamento complexo aquele que emerge, contemporaneamente, do esforço de religar os saberes e se caracteriza pelo caráter interdisciplinar.

Tomando as tendências que vem se afirmando na estruturação dos currículos de formação acadêmica em Geografia, identificamos uma abrangência que recobre núcleos de interesse muito diversificados que dialogam no processo de estruturação dessa ciência, tais como: a formação de professores, a formação de profissionais para as diversas áreas técnicas e de planejamento e a formação de pesquisadores no âmbito da própria Geografia.

Esses núcleos de interesse são permeados por reflexões herdadas desde o nascimento da Geografia Moderna sobre os fundamentos naturais, sociais, históricos, econômicos, políticos e culturais do espaço geográfico apresentando-se do ponto de vista didático com uma divisão em dois grandes campos quais sejam o da Geografia Física e o da Geografia Humana. Em que pese a fragmentação que se apresenta devido a influência do paradigma dominante do positivismo no desenvolvimento da ciência geográfica, vem se afirmando mais recentemente outras áreas desse conhecimento que buscam estabelecer a unicidade desse conhecimento com afirmação de novos núcleos de interesse na formação acadêmica, tais como a Cartografia que vem desenvolvendo os fundamentos técnicos e tecnológicos relacionados a sistemas de representação do mundo e de representação das relações que há no mundo, cuja elaboração tem um amplo alcance para todos os campos de conhecimento e atividades no mundo contemporâneo; a Geografia Regional que tem tratado de fundamentos metodológicos para a pesquisa e o planejamento e que também tem um amplo alcance para diversas áreas do conhecimento e das práticas sociais e políticas; e ainda, a Epistemologia e a História do Pensamento Geográfico que tem investigado os fundamentos teóricos da Geografia Contemporânea realizando um grande esforço crítico para superar os determinismos que marcaram profundamente a formação desse conhecimento.

Podemos afirmar que no âmbito da formação científica e acadêmica a produção científica e filosófica na Geografia tem se caracterizado por um debate teórico e metodológico que pode ser alcançado pelo sentido da religação dos saberes que estão conformados em seu próprio "edifício" interior, apesar de inúmeras contradições e dificuldades que permeiam esse debate, mas que, no entanto, apresenta um potencial e uma abrangência crucial para o processo mais amplo de religação dos demais saberes historicamente produzidos até aqui.

Em que pese o movimento que se verifica no âmbito do debate interno sobre a formação superior acadêmica de Geografia, assistese ainda a manutenção do modelo de fragmentação, especialização e disciplinarização que fortalece as competências tecnocientíficas nas instituições educacionais como se essas competências fossem suficientes para o enfrentamento das contradições, dos paradoxos e indeterminações do mundo globalizado e internacionalizado.

Esta pesquisa parte de uma concepção nuclear que procura os contatos entre a Geografia como área de conhecimento científicoacadêmico e enquanto disciplina escolar como prática social produtora de saberes. Considera-se ainda que a Escola seja um dos espaços de desenvolvimento e de produção de saberes que circulam na sociedade e na cultura entrecruzando as tradições e inovações socialmente produzidas.

Outro marco referencial deste trabalho são as relações que se pode estabelecer entre e as modificações introduzidas no ambiente escolar brasileiro a partir da década de $90 \mathrm{com}$ a implantação da LDB 9394/96 e a importância da Geografia contemporânea. O debate que ocorre atualmente no Brasil sobre o problema de qualidade na Educação reforça a necessidade de caracterizar as demandas que emanam do ambiente escolar, o que deve contribuir crítica e decisivamente para repensar a formação de professores não apenas de Geografia quanto à organização do trabalho educacional e as condições positivas e negativas dadas por uma sociedade informacional, midiática e excludente, dentro da qual as novas 
gerações estão nascendo e se formando.

As últimas décadas do século XX se caracterizam por profundas mudanças no mundo e no Brasil. No campo da educação, o professor vem experimentando condições sociais instáveis e fragmentárias que permeiam todos os campos da vida humana no mundo do trabalho contemporâneo e que atingiram profundamente a cultura e o trabalho educacional também.

A profissão de professor exige enfrentar grandes desafios como cuidar de relações de curto prazo, e ao mesmo tempo estar sempre migrando de uma escola para outra, de um lugar para outro. Como na economia em geral, o trabalho educacional exige também desenvolver novas capacitações conforme as exigências da realidade vão se impondo e valorizando futuras possibilidades mais do que as realizações passadas, desconsiderando o passado.

O professor, entretanto, como a maioria das pessoas, necessita de uma narrativa contínua em sua vida que possa auxiliá-lo a estruturar o sentimento de dignidade pessoal que valoriza e justifica as experiências por que passou e passa. E dar-lhes sentido e significado. As experiências de um professor sempre fazem parte de um trabalho coletivo. E é na vivência do cotidiano da escola que a dimensão coletiva vai se transformando em identidade e possibilitando a percepção profunda do significado histórico, filosófico, político, cultural e social do trabalho educacional.

Está colocado para a formação de professores, em geral, e em particular para o professor de Geografia, o desafio de buscar uma concepção sobre o ser humano e como ele aprende e sobre a sociedade, o mundo, a Geografia. Além disso, não há fórmulas prontas de como ensinar, pois em cada movimento que se realiza para ensinar é preciso fazer escolhas que envolvem uma discussão sobre a Escola enquanto Instituição, numa sociedade complexa, em transição, e cuja finalidade é repensar os conhecimentos socialmente e historicamente elaborados, e que ter acesso a tais conhecimentos é, em primeiro lugar, um direito.

O trabalho docente se consolida a partir de três premissas: a necessidade de desenvolvimento do professor, a consciência dos aspectos políticos envolvidos na ação educativa e a permanente necessidade/possibilidade de experimentação de novos esquemas didáticos.

A procura inesgotável de novos conhecimentos exige uma atualização permanente no campo da ciência que se vai ensinar e também aqueles conhecimentos relacionados com o modo como os indivíduos aprendem, isto é, significa, entre outros aspectos, buscar compreender a dimensão epistemológica envolvida não apenas nos blocos de conteúdos que são escolhidos para ensinar, mas também a dimensão psicológica envolvida no processo de aprendizagem, que apesar de inserido num contexto social, econômico, político, institucional e cultural, sua apropriação se dá de maneira individual. Trata-se de desenvolver a representação do mundo, e mais do que isso: a representação das relações que nele ocorrem.

O desenvolvimento do professor de Geografia se manifesta na possibilidade de delimitar, reconhecer, analisar, identificar e lidar com as interfaces que vão sendo produzidas entre o conjunto de conhecimentos elaborados na esfera cultural científico-acadêmica e o conjunto de conhecimentos produzidos e organizados nas práticas sociais e discursivas da escola.

A consciência dos aspectos políticos envolvidos na ação educativa significa também compreender a dimensão social, política e cultural da Instituição escolar e sua importância como espaço de novas interações para a criança e 0 adolescente na sociedade da qual fazem parte, além da Instituição familiar.

A consciência política impulsiona também a necessidade de conhecer a realidade do aluno e compreendê-lo como sujeito organizador e criador de informação e conhecimento, e não apenas um reprodutor de saberes recebidos ou transmitidos, pois o saber se constrói na mediação e troca entre iguais que vão interagindo e experimentando ter voz ativa de suas vontades e sentimentos, confrontando-se com os demais, e encontrando soluções para seus problemas por intermédio de discussões e expressões próprias de seus questionamentos.

A permanente necessidade/possibilidade de experimentação de novos esquemas didáticos envolve ainda a aquisição de novos conhecimentos e a compreensão das experiências vividas anteriormente. Não se transfere experiência, mas se pode compartilhá-la. Novos esquemas didáticos vinculam-se a interações já vivenciadas e isso não se reporta apenas ao que acontece no interior do ambiente escolar. As características individuais do professor e dos alunos é que apontam a necessidade e determinam as novas possibilidades didáticas.

A tradição metodológica na formação do professor de Geografia valoriza o "estudo do meio", as "interações" e a "interdisciplinaridade", mas no contexto atual de transição paradigmática pelo qual passa a Educação é necessário verificar como está sendo compreendido o papel da Escola e do professor frente à "revolução" contemporânea do meio técnico-científico-organizacional.

É necessário propor novas temáticas e condições para o projeto pedagógico das Instituições educacionais o que significa conhecer as situações instigantes e ousadas que só acontecem nas escolas devido à atmosfera cultural, tecnológica, social e política do fim da década de 70 em diante, e com a qual a Geografia como área de conhecimento acadêmico está comprometida. 
É possível o ensino de Geografia contribuir para a superação da perspectiva de uma escola cujo sentido mais profundo é o do controle social, contribuindo para a emergência de uma escola viva e atual que se inspire na realidade para formar indivíduos que sejam capazes de compreender o mundo em que vivem e agir nele de maneira crítica, transformadora, integradora e humanista.

A formação de professores tem de considerar a dimensão do trabalho pedagógico na superação das desigualdades sociais e, portanto o relevante papel do professor e do ensino de Geografia para o processo social, político e cultural mais amplo.

O desafio de uma prática que atenda as necessidades de preparar os alunos para um mundo em transformação já se impõe aos professores desde os últimos 30 anos, e a implantação da LDB 9394/96 reforçou essa necessidade. Em nossa pesquisa temos verificado o impacto que o paradigma das competências promoveu na estrutura disciplinar do currículo escolar mantido pela Lei Federal de Educação Brasileira. A introdução da problemática dos códigos e linguagens e suas tecnologias nas áreas do currículo apontam a possibilidade de práticas docentes em todos os componentes curriculares que podem romper o isolamento dessas práticas e propiciar condições para a composição de planos e projetos de trabalho apoiados numa perspectiva que atravesse a estrutura curricular disciplinar e produza efeitos no trabalho escolar que precisam ser experimentados e conhecidos para contribuir no processo de superação da fragmentação e especialização das disciplinas convencionais.

Na verdade esta pesquisa está centrada nas expectativas que o professor de Geografia tem em relação ao seu próprio trabalho, especialmente no que diz respeito ao modo como tem refletido sobre suas práticas e até que ponto identifica as relações que pode ocorrer entre as disciplinas escolares e assim contribuir para a valorização do trabalho em equipe que caracteriza a aprendizagem colaborativa entre alunos e alunos, professores e professores e o mais importante, entre alunos e professores. Aqui aparece claramente que é necessário cada vez mais compreender a Geografia que se aprende e que se ensina na escola, e também como se aprende a Geografia. Enfim, o que se aprende e se ensina na escola e também como se aprende na escola.

Não se trata apenas do problema de caracterizar os conteúdos, mas os processos de aprendizagem. Processos que envolvem o fenômeno da linguagem humana em sua diversidade e complexidade além das tecnologias do mundo contemporâneo. Processos que envolvem os saberes e as narrativas elaboradas na ação educacional. Processos que redefinem as relações tempo/espaço da aprendizagem. Processos que distinguem o ser/estar professor.

\section{Contexto da Pesquisa}

Para desenvolver a pesquisa adotamos o espaço institucional da Universidade como espaço de atualização (Curso de Extensão Universitária) e, simultaneamente, espaço de investigação-piloto.

Organizamos e oferecemos, entre abril e agosto de 2009, o Curso "Desenvolvimento Didático-Pedagógico de Aprendizagem Mediada de Geografia para a Educação Básica" com a carga horária de 80 horas visando disponibilizar o progresso do conhecimento na área técnica, científica e acadêmica de Geografia; e, ao mesmo tempo, explorar modalidades de abordagens didáticas junto aos profissionais de educação pública para o estudo de indicações de alternativas para a formação inicial de professores de Geografia no âmbito da Licenciatura. ${ }^{2}$

Após a divulgação do Curso apenas no portal da Faculdade de Filosofia, Letras e Ciências Humanas da Universidade de São Paulo, o curso contou com a participação de 14 professores de Geografia que atuam em escolas públicas e apenas dois atuam também em escolas particulares, sendo que apenas um não exerce ainda a docência. Participaram ainda cinco alunos de graduação que desenvolvem trabalhos de Iniciação à Pesquisa e Trabalhos de Graduação Individual (TGI) na área de Ensino de Geografia, e uma geógrafa que exerce a função de técnica do LEMADI, os quais atuaram como monitores de apoio ao desenvolvimento das atividades inclusive gravando o áudio e o vídeo das atividades realizadas.

$O$ curso teve como objetivos gerais desenvolver atualização de professores no campo da ciência geográfica articulando aspectos científicos, técnicos, culturais e acadêmicos de temáticas contemporâneas de Geografia com a dimensão psicopedagógica envolvida no processo de aprendizagem dessa ciência enquanto disciplina escolar; difundir a metodologia e a didática da Aprendizagem Mediada no ambiente educacional; e, investigar como o professor identifica, analisa, delimita e lida com as interfaces entre a esfera cultural científico-acadêmica e a esfera das práticas sociais e discursivas da escola.

Além desses objetivos, também havia outros objetivos mais específicos tais como valorizar os saberes docentes e a reflexão sobre outros saberes que se produzem e circulam no ambiente escolar; refletir sobre a prática docente e o papel do professor de mediador da aprendizagem; conhecer a metodologia de aprendizagem mediada

\footnotetext{
2 Participaram 11 docentes de diversas áreas do Departamento de Geografia da USP e uma docente convidada da Universidade Estadual de Maringá, os quais ministraram os Encontros Temáticos que visavam o processo de atualização e coordenei junto com a docente vice-coordenadora as Oficinas Didáticas que visavam articular a dimensão didático-pedagógica com o processo de atualização e de pesquisa.
} 
como alternativa experimental para a prática docente; apropriar-se dos fundamentos teóricos para a organização da prática pedagógica de aprendizagem mediada: planejamento da prática, a prática e a avaliação como momento da aprendizagem; indicar princípios e critérios que norteiam a relação professor e aluno; e, elaborar o mapa cognitivo da aula e estimular a modificação do ambiente aula.

A concepção desse curso também se caracterizou por uma perspectiva multidisciplinar e considerou que atualmente é fundamental pensar a Educação de modo integrado, incluindo a própria Universidade como uma Instituição que afinal, está voltada para a dinâmica, o interesse e o desenvolvimento da Instituição Escolar. Apostou-se na possibilidade dos participantes se envolverem no processo de pesquisa e reflexão sobre o estudo de eixos e princípios para pensar inovações no currículo de cursos de formação de professores de Geografia, sabendo que, para dar conta das necessidades contemporâneas da educação no seu cotidiano profissional, aos professores é necessário oferecer a possibilidade de atualização que oportunize ao mesmo tempo um espaço de reflexão sobre as relações entre sua formação e a própria prática e 0 ambiente em que se desenvolve esta prática, a escola, além de compartilhar suas experiências, o que envolve mudanças e apropriação de inovações.

\section{$1{ }^{a}$ Fronteira Teórica: A filosofia da Linguagem - 0 Diálogo como princípio na formação de professores}

A representação que a sociedade, em geral, tem da educação escolar se baseia nas narrativas oficiais de governo, de especialistas que fazem pesquisas e também de diversos outros segmentos da própria sociedade que são veiculados por intermédio da mídia em geral.

A pesquisa "Valorização do Ensino de Geografia na Educação Básica" articulada com uma proposta de curso de extensão se fundamenta numa concepção que envolve interlocutores que dialogam: o pesquisador e o pesquisado, os quais se definem pela convivência e pela interação em um mesmo espaço, à semelhança da concepção de espaço do romance em Bakhtin, "com uma multiplicidade de vozes e consciências independentes e imisciveis, vozes plenivalentes e consciências eqüipolentes, todas representantes de um determinado universo e marcadas pelas peculiaridades desse universo. Essas vozes e consciências não são objeto do discurso do pesquisador, são sujeitos de seu próprio discurso".

A própria pesquisa é concebida como diálogo, segundo a concepção de diálogo em Bakhtin que, em última instância, aponta um dos dilemas contemporâneos das ciências humanas que é a negação da pesquisa entre sujeito e objeto, mas ao contrário introduz a concepção de que nas ciências humanas a pesquisa envolve a relação entre sujeito e sujeito.

A proposta de realizar a pesquisa no espaço e tempo de um curso de atualização produziu uma base dinâmica para o tipo de investigação proposta em que temáticas geográficas e temáticas didáticas são analisadas no próprio processo didático, cognitivo e dialógico do Curso de Desenvolvimento da Aprendizagem Mediada de Geografia.

0 professor é identificado nesse trabalho como o sujeito central da prática social e cultural da educação contemporânea, buscando na própria narrativa desse sujeito os aspectos e elementos relevantes e críticos que caracterizam essas práticas, inclusive entre o pesquisador e o pesquisado. A pesquisa é um diálogo de natureza investigativa.

A narrativa do principal sujeito do processo educacional escolar, o professor, é pouco conhecida, até porque, na verdade, há poucos espaços/tempos para se ouvir os professores fora do ambiente em que ocorre seu trabalho profissional. E é nesse sentido que essa pesquisa procurou também ampliar o movimento de relação dos professores com a Universidade e aprofundar o diálogo entre a Educação Básica e a Educação Superior.

Foi uma escolha iniciar a pesquisa com as narrativas dos professores, isto é, como estão entendendo o que está acontecendo atualmente com o ensino de Geografia no Brasil para trocar experiências e pensar as práticas de formação de professores a partir de suas experiências e narrativas que podem indicar elementos para o próprio desenvolvimento da pesquisa e para a reflexão sobre a docência e o papel do professor.

A formação do professor de Geografia, portanto não é desenhada ou pensada de fora, a partir da pesquisa. Mas, a partir do interior da própria pesquisa, por intermédio da palavra falada, da narrativa sentida e ouvida dos indivíduos que já são professores de Geografia e que vivem a permanente contradição de uma formação que se choca e se defronta com as necessidades da Educação contemporânea e que sentem permanentemente a necessidade de dialogar sobre essa formação, revendo-a permanentemente.

Às vezes, sem perceber que é disso que se trata, como se houvesse a necessidade de uma metacrítica de si próprio, e não apenas quanto à atualização de saberes e conhecimentos que são necessários ao seu trabalho, mas, e principalmente, até como

${ }^{3}$ BRAIT, B. (org.) Bakhtin: Conceitos-Chave. São Paulo: Editora Contexto, 2008. 223 p. 
uma necessidade da linguagem, comunicação e expressão sobre sua própria realidade de trabalho. Às vezes, como necessidade perante outros interlocutores, como os alunos, por exemplo, que permanentemente desafiam toda experiência da comunicação humana, pois a realidade no ambiente escolar se apresenta sem um padrão, o que indica a possibilidade de orientar as práticas pedagógicas à luz de teorias que dêem suporte para a compreensão dessas práticas e ao mesmo tempo possibilitem testar e experimentar práticas pedagógicas novas e inovadoras também.

Então, a pesquisa se baseia também numa troca. Não apenas simbólica, mas de técnicas e vivências e experimentações em que os participantes da pesquisa e do diálogo vão tecendo o espaço onde se realiza a metacognição de suas experiências e de seus processos de trabalho.

Trata-se de resgatar o sentido do vivido do professor no diaa-dia e desvendar-lhe o potencial que segundo Bakhtin, "o outro precisa chegar a ser palavra, quer dizer, iniciar-se num contexto verbal e semântico possivel para se revelar. Restaurar o espaço do sentido significa, portanto, devolver ao sujeito não apenas seu discurso, mas a autoria de sua palavra e o lugar do seu desejo no confronto com a realidade." 4

É nesse sentido que se acredita poder desenhar ou descobrir um perfil que possa ser compartilhado a muitas vozes que podem se entender e que é, ao mesmo tempo, o do professor mediador, segundo Feuerstein e do pesquisador segundo pressupostos dialéticos da formação do pesquisador em Ciências Humanas.

Do ponto de vista da pesquisa propriamente dita, trata-se de procurar por intermédio do diálogo, os elementos universais que caracterizam o perfil e o papel do professor. Cada professor, cada indivíduo tem suas próprias características, porém na condição e função social de professor, há características e aspectos que são universais e que podem auxiliar na orientação de um currículo novo de formação de professores.

Assim a lógica que preside a pesquisa não é a de desenhar uma formação, mas prospectar os elementos universais que possibilitem desenhar uma formação de tipo novo.

Aqui estão envolvidos aspectos políticos no sentido de realizar uma proposta de mudança na formação de professores que se orienta não por objetivos externos às práticas docentes, mas em elementos internos encontrados nas narrativas do trabalho docente do mundo contemporâneo a partir de um sujeito individual que vai auxiliando a desvendar o sujeito coletivo que vive essa realidade. É uma inversão que busca provocar efeitos qualitativos para a produção do trabalho docente.

Os aspectos universais envolvidos estão identificados com as relações que vão se construindo no ambiente escolar que apresentam múltiplas naturezas, mas que na sala de aula são determinados por relações entre indivíduos instituídos (aluno e professor) que dialogam o tempo todo sem um método próprio e acima de tudo, diálogo impregnado do caráter institucional que recobre 0 ambiente escolar, o qual infunde conseqüências permanentes para a finalidade da Escola que, em última instância, tem de trabalhar com conhecimentos socialmente produzidos e relevantes para o desenvolvimento da sociedade em curto, médio e longo prazo inibindo, muitas vezes, o potencial da escola de se reinventar enquanto instituição escolar.

O tipo de diálogo que estamos construindo com essa pesquisa já aponta alguns elementos bastante determinados acerca dos pressupostos que presidem a formação em geral dos professores e reforça a necessidade de uma crítica radical na tendência que 0 debate educacional apresenta atualmente no sentido de reforçar a formação metodológica a qual é acentuada pelo destaque e importância dada às técnicas didáticas, a duração da formação que é de alta velocidade, imprimindo rapidez com a adoção de alternativas de cursos à distância.

Ora, os professores já profissionalizados que atuam na educação, especialmente pública, verbalizam a necessidade de tempo para refletir sobre suas práticas e sobre seus alunos. Explicitam também que é necessária uma condição nova de trabalho em que seja possível discutir e dialogar entre pares acerca dos problemas de aprendizagem de seus alunos e alternativas sobre os aspectos curriculares no âmbito das ciências em geral, e também no campo comportamental e da natureza mesma da aprendizagem. Isso requer atualizações constantes não apenas no campo científico acadêmico, mas também nas atuais condições de organização das atividades escolares, em que não se considere apenas os tempos de aulas propriamente ditas, mas também os tempos de preparação das aulas, de estudos e pesquisa e de reflexão propriamente dita. Os tempos da ação, reflexão e ação.

Tendo acesso ao conhecimento dos processos cognitivos subjacentes a toda e qualquer aprendizagem, os professores admitem que em sua formação, falta uma base teórica que oriente e fundamente as suas práticas. Melhor dizendo, sentem-se despreparados em relação aos problemas comportamentais que vão emergindo no processo pedagógico com os alunos e com os demais

\footnotetext{
${ }^{4}$ IN: SOUZA, S. J. Infância e Linguagem: Bakhtin, Vygotsky e Benjamin Coleção Magistério: Formação e Trabalho Pedagógico. São Paulo: Papirus Editora, 1994.173 páginas.
} 
professores, e acima de tudo na compreensão do seu papel e função em relação às demandas desse tipo que aparecem cotidianamente no trabalho educacional e que interferem na qualidade da aprendizagem dos alunos e descaracterizam a finalidade última da Escola.

\section{$2^{\mathrm{a}}$ Fronteira Teórica: Ciências da Cognição - A Aprendizagem Mediada como Didática - primeiras aproximações}

Adotamos também na pesquisa que estamos realizando a concepção de Reuven Feuerstein sobre mediação a qual contribui para a compreensão da importância dos processos cognitivos subjacentes aos processos envolvidos na aprendizagem em geral, e colabora, decisivamente, para desvendar a origem do desenvolvimento cognitivo diferenciado dos indivíduos, e simultaneamente, indicar um modo de compreender a natureza das interações humanas, especialmente, as educacionais e familiares. Trata-se de uma concepção que apresenta um interesse e abrangência muito grande para os estudos e as pesquisas sobre as relações professor-aluno e os processos de aprendizagem decorrentes dessa relação.

Diante da necessidade colocada para a educação contemporânea quanto à necessidade de repensar a formação de professores, a contribuição de Feuerstein pode ser decisiva, já que ele considera que as diferenças no desenvolvimento cognitivo dos indivíduos não se explicam apenas por fatores genéticos ou ambientais, sócio-econômicos ou culturais. Apesar de considerálos e de não negar seus efeitos, Feuerstein considera crucial 0 fator próximo, isto é, a natureza mesma das interações humanas em etapas decisivas do desenvolvimento que ele denominou de experiência de aprendizagem mediada.

Reuven Feuerstein define a experiência de aprendizagem mediada como "a qualidade da interação do ser humano com seu ambiente. A experiência de aprendizagem mediada é muito mais que um simples modelo pedagógico, comporta a explicação dos processos cognitivos como subproduto da transmissão cultural. De fato, a aprendizagem se dá por intermédio de duas modalidades de interação com seu meio: a exposição direta aos estímulos, considerada como a maneira mais penetrante, na qual a interação do organismo-ambiente afeta o organismo; e, a experiência de aprendizagem mediada, na qual as interações do humano com seu ambiente são mediadas por outra pessoa que atua intencionalmente". ${ }^{5}$

$\mathrm{O}$ trabalho desse autor além de se apoiar em elementos teóricos da psicologia integra-se com outras plataformas teóricas como a da neuroplasticidade, da biologia e da cultura, apresentando um interesse imediato para repensar o papel da escola, os objetivos, os princípios e a didática dos processos de ensino e de aprendizagem.

Feuerstein elaborou a Teoria da Modificabilidade Cognitiva Estrutural, que considera a autoplasticidade do organismo humano e tem trabalhado também na elaboração da Teoria dos Ambientes Modificantes que dão ao sistema de seu pensamento sobre a experiência de aprendizagem mediada "um significado universal independente da linguagem ou do conteúdo no qual ocorre a interação intermediada e representa uma característica única de interação humana e se concebe como determinante da autoplasticidade do organismo humano desempenhando uma função primordial na determinação das tendências evolutivas e das mudanças importantes que ocorrem no funcionamento mental humano. A ausência de experiência de aprendizagem mediada diminui a plasticidade do organismo que pode dar lugar à carência ou redução da modificabilidade, como no caso dos indivíduos para quem a exposição direta aos estímulos tem um efeito limitado, inclusive quando esta exposição direta é de uma natureza operacional ativa... tem demonstrado que a modificabilidade é possivel e que o ser humano tem de dar-se a oportunidade de beneficiar-se dela e de materializar a opção de desenvolvimento que esta oferece.". 6

Ao se integrar ao espaço de investigação com as Oficinas Didáticas que se pautam pela reflexão acerca da prática docente, oportunizou-se ao professor a vivência da aprendizagem mediada e, simultaneamente, o acesso ao modelo teórico da Experiência de Aprendizagem Mediada de Reuven Feuerstein, já que esse modelo não faz parte normalmente dos currículos de formação de professores, e ainda pode ser compreendido como uma alternativa experimental de inovação para as práticas do professor de Geografia.

A necessidade de buscar inovações para desenvolver a prática docente apareceu logo no início do Curso quando foi dada a oportunidade para os participantes expressarem as suas expectativas em relação ao Curso que se iniciava. Além da busca por inovações, outros aspectos muito complexos relacionados às características do ambiente escolar, às condições de trabalho e mesmo à formação de professor apareceram nas narrativas

\footnotetext{
${ }^{5}$ Entrevista de Reuven Feuerstein a Sergio Noguez Casados IN: Revista Electrónica de Investigación Educativa Vol. 4, No. 2, 2002 (tradução do espanhol de nossa inteira responsabilidade).

${ }^{6}$ Idem ao anterior.
} 


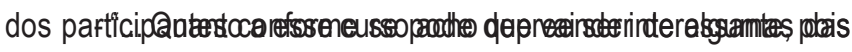

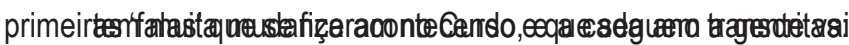
vendo novas imposições de como trabalhar, como fazer, e a cada hora já muda totalmente e de repente a gente está fazendo tudo errado, e agora quem sabe a gente pode trilhar juntos e ver as novidades".

- "... Nesse curso eu vim buscar um pouquinho de saber. A gente fala tanto com 12 aulas por dia, falando o tempo todo, a gente se sente esgotada, né? Então eu vim beber um pouquinho de saberes novos, só isso".

- "... Meu interesse é atualização. Há 40 anos eu procuro sempre renovar um pouquinho".

- "... atuo há uns 3 anos na área de ensino, me formei aqui na USP, e atuo numa escola da zona sul de São Paulo, na região do Campo Limpo, é uma região periférica, problemática, e estou aqui para aprender novas experiências. É isso".

- "... formei-me aqui na USP em dezembro passado no bacharelado e licenciatura, e ingressei na prefeitura e estou dando aulas... há um mês e pouco. Então para mim tudo está sendo novidade, e estou tendo dificuldade justamente por não ter tido nenhuma experiência anterior".

- "... estou na rede estadual há uns 5 anos. Meu objetivo nesse curso realmente é a troca. Troca de saberes com outros colegas. Como a gente vai se adequando e como os outros colegas fazem. Eu me sinto, às vezes, sozinha para achar um caminho. Meu objetivo realmente é a troca".

- "... estou vindo nesse curso pela seguinte situação: ... toda a escola está muito distante da academia... a gente está com o pensamento muito retrógrado, muito mesmo. Não se utiliza os horários coletivos para discutir. E não se discute nada. Só papelada, só as coisas que você tem de entregar. Não se discute o que os colegas estão dando, nem em termos de troca de pensamentos mesmo, não estou falando de atividades, estou falando de pensamentos mesmo. Nem com seus colegas de área. Fica aquela coisa de um entra e outro sai... E não adianta querer mudar as coisas sozinho. $\mathrm{O}$ colega tem de estar junto. Fica só no mundinho dele. Está muito difícil".
- "... o que me motivou a procurar esse curso foi a angústia de me sentir sozinha, como alguns colegas já falaram, e não ter essa troca de experiências. Acho que a troca de experiências entre os professores é muito importante e na escola isso não ocorre".

- "... Acho que é extremamente urgente e necessário que aconteça esse encontro para que justamente a Academia possa ver e visualizar a rede de ensino público e a rede possa ver o que se faz na Academia. Esse é meu interesse também."7

Nessas narrativas se destaca, em primeiro plano, a necessidade intensa de diálogo na proporção de sua ausência quase que absoluta. E ainda a necessidade de inovação. É como se soubessem que deve haver alguma alternativa, mas que eles não conhecem. É importante salientar que os professores que se inscreveram e participaram do curso o fizeram espontaneamente e sem interesse corporativo em alguma promoção na carreira.

Os professores participantes puderam se apropriar de alguns fundamentos teóricos para pensar a reorganização de suas práticas pedagógicas e dos princípios e critérios que norteiam a relação do professor mediador da aprendizagem com seus alunos, bem como a necessidade e possibilidade de modificação do ambiente aula, além do contexto escolar como um todo.

A abordagem teórico-prática sobre a aprendizagem mediada que orientou as atividades nas Oficinas Didáticas possibilitou que 0 grupo de professores participantes fossem resgatando seus próprios saberes docentes e acumulando uma reflexão sobre a potencialidade e o valor das teorias de Feuerstein para modificar a metodologia do trabalho em sala de aula e aumentar o desempenho de aprendizagem de seus alunos.

Com uma postura bastante responsável, cuidadosa e criteriosa acerca da adoção de uma teoria nova que sempre causa algum receio, identificaram a necessidade de mais estudo e aprofundamento dessa tendência, mas compreendendo a importância de trabalhar a partir de princípios e critérios que norteiem a relação professor e aluno.

Demonstraram disposição para a possibilidade de experimentar

${ }^{7}$ Trechos de algumas manifestações dos participantes realizadas no início do curso e registradas em vídeo. 
novos esquemas para modificação do ambiente aula, e acima de tudo a perspectiva de estudar mais para realizar a elaboração do mapa cognitivo das situações de aprendizagem como um aprimoramento do seu trabalho no ensino e aprendizagem de Geografia conforme se pode perceber pelos depoimentos registrados após uma semana do encerramento do curso e que seguem transcritos:

- "... O curso para mim foi um choque. Um choque de idéias, um choque no marasmo, um choque entre as diferenças de idade dos participantes... O curso para mim foi de fundamental importância porque deu uma chacoalhada nas idéias que estavam acomodadas... a teoria do Feuerstein não é uma coisa que você vai assimilar num primeiro momento, a primeira impressão é assim: vale a pena você conhecer, tentar aplicar principalmente em Geografia, mas confesso que tive dificuldades em entender aqueles passos do mapa cognitivo, mas foram de grande valia, não resta dúvida. 0 que foi marcante foi saber como o Feuerstein começou a mediar crianças dos campos de concentração, isso para mim foi marcante. Saber que você pode mediar, e que você tem de encontrar os caminhos para chegar até 0 aluno. Isso que ficou para mim. Estou tentando colocar em prática. Tenho uma $6^{\mathrm{a}}$ série, sabe aquelas que a gente rotula e que você não tem prazer de entrar na sala porque você sabe que vai encontrar um ambiente de bagunça, de desrespeito, de tudo. É nessa classe que estou tentando aplicar. Não consegui ainda trabalhar em subgrupos com esses alunos, fazer os subgrupos está muito difícil, mas eu não vou desistir. É nessa classe que eu vou ver se consigo fazer alguma coisa, não sei ainda como, mas eu acredito que é com a mediação. $O$ tema que estou tentando trabalhar com eles é o IDH..."

- "O que mais chamou a minha atenção foi a questão do mapa cognitivo. Ele é importante e é uma questão que precisa preceder e acompanhar o desenvolvimento do mapa conceitual de um determinado conceito científico... Não me sinto muito à vontade em aplicar sem conhecer mais a fundo a teoria. Pretendo estudar mais..."

- “... O curso possibilitou uma reflexão sobre novas práticas e metodologias de mediação com meus alunos... Aaprendizagem mediada permite a gente alcançar níveis mais altos com os alunos. Ainda não tive tempo de fazer uma mudança nos planos de trabalho, mas pretendo introduzir elementos de localização com a mediação... Se a gente trabalhar com a teoria do Feuerstein pode esquecer a questão do tempo de duração prevista para os temas de Geografia..."

- "... O curso foi muito válido porque como sou iniciante, tive tantas dificuldades com o trabalho de sala de aula, que em alguns momentos tive vontade até de desistir de ser professor. Esse curso me ajudou a ter outra visão que eu não tive durante a minha licenciatura, visão prática de sala de aula. 0 curso apresenta propostas e não só debate de idéias. Foi muito proveitoso nesse sentido... Tomar contato com a metodologia do Feuerstein me deu uma saída. Eu fiz a licenciatura que teve muitos pontos positivos, mas em termos do que fazer em sala de aula, eu me senti e ainda me sinto muitas vezes perdido. Essa metodologia de poder fazer o aluno se desenvolver cognitivamente foi algo que me acrescentou muito... Não houve tempo ainda para aprofundar a teoria e o método do Feuerstein. Na verdade foi um contato, para se saber que existe essa possibilidade, mas falta desenvolver. Faltou tempo... Penso que é relevante a questão de não se ficar tão focado no conteúdo e estimular o desenvolvimento cognitivo do aluno. Fazer com que 0 aluno ao trabalhar em algumas atividades possa desenvolver algumas ferramentas que possibilitem a ele desenvolver qualquer tipo de trabalho, na vida inclusive, se desenvolvendo de tal forma que ele consiga se desenvolver na sua própria vida. Isso para mim foi o principal. Eu tenho começado a fazer alguma coisa, eu tenho alunos com muita dificuldade de aprendizagem de leitura e de escrita, com problemas de ordem familiar, dou aula numa comunidade muito carente, com alunos muito difíceis e eu não sabia como lidar com isso. Uma coisa que eu comecei a fazer é trabalhar com eles permanentemente em grupos como foi sugerido, e tenho feito atividades que focalizem a construção de algo para chegar num resultado, como mapas, gráficos... algo que tem de chegar num resultado. Tem sido válido porque os alunos saem daquela rotina de serem copistas e serem presos a copiar só para cumprir tabela e obter uma nota. Trabalhando em outro foco e saindo da prática de aula expositiva que eles não gostam e ficam apáticos, o ambiente da aula muda. Quando se coloca os alunos em grupos começam a aparecer dúvidas e passam a procurar o professor que pode dar uma atenção maior para um grupo reduzido de alunos e aí você consegue mediar de forma mais prática e efetiva. Não tenho certeza de que vai dar sempre certo. Eu quero continuar nessa visão e me aprofundar e manter contato para não perder a possibilidade de ampliar o que já se conseguiu..." 
- "... Eu estava aguardando um curso como esse há muito tempo... o mais relevante é a forma de trabalhar a cabeça do aluno... e fazer o aluno perceber a própria capacidade de aprender. É você trabalhar a Geografia fazendo questionamentos mais precisos na sala de aula, não entregar o conteúdo pronto e fazer com que 0 aluno retorne com um conteúdo que ele realmente se aproprie. Foi uma técnica muito interessante, pois não trabalhamos com textos, mas fomos trabalhando o lado psicológico da aprendizagem e nós, de certa forma, vivenciamos o papel e a situação do aluno da escola fundamental, aprendemos a observar a paisagem de maneira diferente e fazer o aluno aprender a aprender. Quando o professor faz a mediação de modo correto, ele consegue aprender de fato. Foi muito interessante... Já comecei a trabalhar, apesar de não termos tido todos os fundamentos de Feuerstein, fui fazendo uma revisão do que eu já tinha estudado até em outras teorias. Na verdade estou modificando 0 modo de preparar as aulas. Antes eu preparava mais 0 conteúdo das aulas, o que eu esperava dos alunos em termos de conteúdos. Na verdade agora, passei a preparar melhor as aulas no sentido de desenvolver algumas capacidades que eles até então não tinham. Comecei a pensar no lado das habilidades de aprendizagem. $O$ conteúdo é importante, mas também é importante o que você quer que o aluno desenvolva cognitivamente com aquele conteúdo..."

- "... o que foi relevante no curso foi que ele trouxe a questão essencial sobre o ensino. Não adianta o Estado propor conteúdos de ensino, conteúdos prá cá, conteúdos prá lá. A questão essencial é se pensar na avaliação do aluno... Deu para ter uma idéia da teoria de Feuerstein. Penso que a idéia de uma teoria é fundamental para fazer avançar a educação. A proposta de Geografia de São Paulo é um avanço, mas ainda é muito conteudista. Não temos o mapa cognitivo das situações de aprendizagem sugeridas e isto faz muita falta para o desenvolvimento do professor... Estou colocando em prática alguns aspectos das teorias estudadas... tentando aplicar o mapa cognitivo no planejamento das situações de aprendizagem mediada..."

- "... Considerei o curso muito válido, não conhecia as teorias do Feuerstein, e foi muito bom para abrir caminhos. Acredito que é possivel aplicar a teoria nas aulas. 0 curso veio numa hora em que os professores estavam buscando alternativas... até fiz inscrição no concurso da prefeitura porque o curso despertou meu interesse para ser professor..."

- "... O curso estimulou repensar o ensino de Geografia, e também 0 ensino como um todo. Repensar a prática do professor, sua metodologia, sua didática e também foi destacado um aspecto que não vejo ser discutido nesses onze anos de magistério, que é o como 0 aluno aprende, como 0 aluno raciocina e aprende os conteúdos... as Oficinas Didáticas sobre as teorias de Feuerstein foram proveitosas mas eu ainda sinto dificuldade em como planejar uma sequência didática segundo a proposta de Feuerstein, e penso que num próximo curso com mais bibliografia, e estudando mais a metodologia a gente avança ... Tentar aplicar, eu ainda não consegui. Foi focalizado bastante o trabalho em grupos e um dos obstáculos seria a quantidade de alunos e também por conta de uma resistência do professor e, aqui me incluo nisso, por causa de uma longa tradição de pensar o ensino com uma centralidade no professor, e é necessário você pensar no outro, e isso é difícil porque não se muda de repente, não é uma coisa para já. A teoria é válida e talvez consiga levar o aluno a desenvolver uma prática que possa contribuir com 0 que a vida está exigindo deles..."

- “... A experiência do curso veio acrescentar bastante à minha experiência. Eu estou muito entusiasmada após o curso e estou com muita esperança de dar novos rumos para o meu trabalho e contribuir com a educação... Gostei das oficinas didáticas, mas percebo que os desafios são grandes e talvez eu precisasse me aprofundar no assunto. $E$ as dificuldades em escola quando a gente não tem sala ambiente? Estou tentando aplicar alguns aspectos, mas não dá ainda para sentir os resultados. Mas estou começando a colocá-los em grupos e eles não tem esse hábito. Nem todos os alunos a gente consegue atingir. No começo foi desesperador. Eu não tive muito tempo devido ao recesso escolar. Mas agora eles já começam a se entrosar e está ficando legal. Sinto ainda um pouco de medo com essa abordagem nova. Mas eu fiquei muito interessada e entusiasmada com esse modo novo. Acho que está sendo muito bom ...."

- "... O curso foi interessante, as pessoas estavam entusiasmadas com os temas que eram diferentes. $O$ fato de olhar 0 aluno a partir de alguma função cognitiva foi a chave desse curso. Confesso que mudou muito minha concepção 
de ensino a concepção de Feuerstein. A relação com 0 pensamento de Bakhtin eu penso que é uma perspectiva inovadora de análise e interpretação e ao mesmo tempo é uma forma de crítica a estas propostas curriculares que estão sendo impostas pelo Estado e que não são suficientes para resolver os problemas que as crianças tem de dificuldades na escola. Essa teoria fez eu pensar muito sobre as teorias do ensino... Apesar de minha formação ser crítica em relação à Psicologia, reconheço que Feuerstein tem uma abordagem muito interessante no que diz respeito a estudar as funções cognitivas, mas em relação também à privação cultural. 0 que mudou para mim, foi a possibilidade de identificar quais são as privações que o aluno apresenta e ao mesmo tempo analisar as deficiências que eles tem no processo das aulas. Eu, particularmente, já estou começando a mudar um pouco a minha aula, e eu falo mudar um pouco porque a escola é muito dialética e a gente tem câmeras espionando a gente o tempo todo, diretores, supervisores, e estou conseguindo aplicar aquilo que eu aprendi no curso e que está dando muito resultado. E não só os professores de Geografia deviam conhecer essa abordagem, mas todos, porque de fato são teorias que ajudam a mudar o ensino, 0 ambiente da aula e 0 jeito de se trabalhar... Recentemente procurei trabalhar na $6^{a}$ série o sistema de orientação espacial. Obviamente eu não tinha o material do Feuerstein para poder aplicá-lo, então utilizei o material da proposta naquilo que eu queria que eles atingissem. Tivessem noção dos sistemas de informação. Foi difícil, mas consegui fazer alunos aprenderem e a localizar o norte, o sul, enfim os pontos cardeais. As dificuldades foram em termos das condições escolares. Tenho hoje cinco salas de $6^{\mathrm{a}}$ séries com 50 a 55 alunos. Em aulas com duração de 50 minutos cada, confesso que fica difícil preparar a sala como ambiente modificante, organizar os alunos para se concentrar e, além disso, gente passando no corredor, coordenador passando para avisar do Play Center, isso quer dizer foi complicado, mas foi gratificante. Acredito que se tivéssemos as condições de um espaço com carteiras e mesas voltadas a esse tipo de aprendizagem seria muito bom, porque funciona... Pretendo saber muito mais sobre a teoria de Feuerstein e me aprofundar mais..."

\section{Considerações Finais}

Este artigo é uma comunicação das primeiras aproximações de resultados que sistematizamos com a pesquisa "Valorização da Geografia na Educação Básica". Temos trabalhado muito para elaborar outras aproximações relacionadas à $3^{\text {a }}$ Fronteira Teórica da Formação de Professores que é a própria Geografia, enquanto uma ciência que trabalha com sistemas de representação do mundo e da representação das relações que há no mundo. Assim entendida, a Geografia pode contribuir para o desenvolvimento do pensamento complexo, pois articula conhecimentos dos campos da Natureza, Sociedade e Tecnologia que nos currículos de formação geral de professores passaria a ter um papel relevante na formação dos profissionais que podem preparar a instituição escolar para a transição paradigmática no sentido da religação de saberes formando as futuras gerações, que devem se beneficiar muito com esse processo.

O Grupo de Estudos ${ }^{9}$ formado a partir do Curso de Extensão vai se dedicar ao estudo dos campos da Filosofia da Linguagem, das Ciências da Cognição e da Geografia como pensamento complexo.

\footnotetext{
${ }^{8}$ Trechos de algumas entrevistas com os participantes realizadas após o encerramento do curso e registradas em vídeo.

${ }^{9}$ Foi criado o "Círculo de Estudos das Fronteiras Teóricas para Formação de Professores" que passa a se reunir no LEMADI - Laboratório de Ensino e Material Didático do Dept ${ }^{\circ}$ de Geografia da FFLCH - USP a partir de setembro de 2009.
} 
MIRANDA, M.E. (2010). Contribution to current debate on Teacher Education in Brazil: for the training of future generations in view of the reconstruction of socio-cultural. Revista do Departamento de Geografia, n. 20, p. 11 - 22.

Abstract: This article is a communication on the fistt aproaches to the results obtained with the research "Valorização da Geografia na Educação Básica", in its pilot phase, carried out between April and August 2009, during the Universitary Extension Course named "Desenvolvimento Didático-Pedagógico de Aprendizagem Mediada de Geografia para a Educação Básica". The research deals with the essential interfaces and linkages between teaching Geography in primary education and areas of interest that characterize teaching and research trends in Geography as an scientific and academic field, which consolidate its growing importance as a complex knowledge. Geography, as a school discipline, is here understood as an social practice essential to the formation of free and independent representations of both the world and of the existing relations inside the world, that circulate in society and culture. This qualitative research sought to characterize and understand the demands that are currently presented to teacher training through the narrative of teachers themselves on some everyday learning problems faced during their work, which highlights their need to question, radically, the theoretical and philosophical trends of scientific-technical nature that has predominated on the current debate over teacher's training in Brazil. What the research indicates, to date, on the contrary to what might have seemed, is the need to further enrich theoretical and philosophical teacher training. It has been adopted, in this research, the concepts of mediated learning by Reuven Feuerstein, of dialogue in Mikhail Bakhtin, and also the idea of complex thought and the rewiring of knowledge historically produced and separated according to Edgar Morin. The concepts adopted form what we call "theoretical boundaries for teacher training".

Keywords: Geography; Complexity; Teacher Training; Mediated learing; Dialogic action.

Recebido em 05 de dezembro de 2009, aceito em 10 de agosto de 2010.

\section{Referências}

BRAIT, B. (org.) (2008) Bakhtin: Conceitos-Chave. São Paulo: Editora Contexto. 223 páginas.

Entrevista de Reuven Feuerstein a Sergio Noguez Casados (2002) IN: Revista Electrónica de Investigación Educativa Vol. 4, №. 2. (tradução do espanhol de nossa inteira responsabilidade).

MORIN, Edgar (2007)A Religação dos Saberes: o desafio do século $X X I$. Rio de Janeiro, Bertrand do Brasil 588 páginas.

SOUZA, S. J. (1994) Infância e Linguagem: Bakhtin, Vygotsky e Benjamin Coleção Magistério: Formação e Trabalho Pedagógico. São Paulo: Papirus Editora. 173 páginas. 